\title{
Anti-Choking Suction Devices for Foreign Body Airway Obstruction in Children. Would Parents and Kindergarten Teachers be Able to Use Them Without Training?
}

\author{
Aida Carballo Fazanes \\ Universidade de Santiago de Compostela - Campus de Santiago: Universidade de Santiago de \\ Compostela \\ Cristian Abelairas-Gomez ( $\sim$ cristianabelairasgomez@gmail.com ) \\ Universidade de Santiago de Compostela - Campus de Santiago: Universidade de Santiago de \\ Compostela https://orcid.org/0000-0002-1056-7778

\section{Emilio Rodríguez-Ruiz} \\ University Hospital of Santiago de Compostela: Complejo Hospitalario Universitario de Santiago de \\ Compostela

\section{Roberto Barcala-Furelos} \\ University of Vigo: Universidade de Vigo

\section{Antonio Rodríguez Núñez} \\ University Hospital of Santiago de Compostela: Complejo Hospitalario Universitario de Santiago de \\ Compostela
}

\section{Research Article}

Keywords: Airway management, children, foreign body airway obstruction, relatives, schoolteachers, simulation.

Posted Date: July 1st, 2021

DOl: https://doi.org/10.21203/rs.3.rs-647309/v1

License: (c) (i) This work is licensed under a Creative Commons Attribution 4.0 International License. Read Full License 


\section{Abstract}

There is limited scientific evidence on the brand-new suction anti-choking devices as alternative or complementary tools for the treatment of foreign body airway obstruction (FBAO). However, they are already available in some public places. With the hypothesis that laypersons would not use them properly we have carried out the present simulation study.A randomized crossover trial study in a simulated FBAO scenario was conducted. Forty-two parents and eight kindergarten staff without knowledge about antichoking devices voluntarily participated. Participants had to solve a simulated FBAO situation in three randomized scenarios: 1) Following the current choking international guidelines, 2) Using the LifeVac $\circledast$ device, and 3) Using DeCHOKER ${ }^{\circ}$ device, according to the instructions provided by manufacturers. Data from 51 participants (54.9\% female) were analyzed. Higher success rate was achieved with the LifeVac $\circledast$ and DeCHOKER ${ }^{\circledR}$ devices in comparison with the standard FBAO protocol (median [IQR]: 100.0\% [83.0100.0], 100.0\% [75.0-100.0], and 50\% [38.0-75.0] respectively; $p=0.004)$. No significant differences were observed between both anti-choking devices $(p=0.796)$. The procedure time was significantly shorter with the LifeVac® device $(p<0.001)$.

Conclusion: Untrained laypeople, under simulated conditions, are able to properly handle LifeVac ${ }^{\circledR}$ and DeCHOKER® anti-choking devices according to the manufacturer's instructions in less than one minute. However, they have difficulties to perform the current recommended choking protocol. Further studies are needed to confirm whether the new devices could have a role in the FBAO management.

\section{What Is Known}

- Anti-chocking suction devices has recently emerged for the management of foreign body airway obstruction.

- Foreign body airway obstruction is relatively frequent in children.

- There is insufficient evidence for recommend or not recommend the use of anti-chocking suction devices.

\section{What is new}

- Laypeople were able to use anti-chocking suction devices under simulated condition.

- Participants had difficulties to carry out the recommended choking protocol even being provided with the instructions.

\section{Introduction}

Foreign body airway obstruction (FBAO) events are relatively common in children [1], particularly in preschool age because their behaviour predisposes to it [2]. FBAO situations represent a potentially life- 
threating emergency that requires immediate recognition and intervention [3] since victims may quickly progress to unresponsiveness and death [4].

Bystanders often intuitively intervene in case of FBAO. In the case of children, most choking events happen at home or at school, where children spend most of their time [5]. Therefore, parents and/or teachers are more likely to be the first responders in such cases. Interventions required will differ depending on whether it is a mild or severe airway obstruction. Current guidelines recommend encouraging to cough while coughing is effective (mild airway obstruction) and afterwards the combination of back blows and abdominal trust ("Heimlich maneuver") [6] or chest thrust (in children under one year of age) (severe airway obstruction) $[4,7]$.

However, despite FBAO being an important health problem, the evidence available to support these guidelines is weak [8-12]. This, in addition to the risk associated with abdominal thrusts in children (risk of thoracic, vascular, and gastroesophageal injury) [13], leads to a continuous search for a universally accepted and successful technique for FBAO removal.

Recent treatments proposed for the management of FBAO are anti-choking suction devices. Currently, two such devices are commercially available: LifeVac ${ }^{\circledR}[14]$ and DeCHOKER ${ }^{\circledR}$ [15]. Both are relatively simple and non-powered portable devices. They aim to generate a strong negative pressure in the oral airway that helps to relieve airway obstruction. By manufacturers' own choice, they recommend in the product leaflets and websites to apply them when the standard choking protocol fails.

These anti-choking devices are Class 1 registered by the Food and Drug Administration (FDA) for use in a choking emergency, simple registration for low-risk devices that are exempted from further FDA clearance or formal approval and have not passed through a submission and assessment process [8]. Nevertheless, they are widely available for anyone to use them in locations such as airports, hotels, or shopping centers [16]. A recent systematic review on the anti-choking suction devices showed that, given the limited scientific data and biased trials that have tested the use and effectiveness of these devices, there is insufficient evidence for or against their use [17]. Likewise, based on of the limited scientific literature on these devices, the International Liaison Committee on Resuscitation has revealed the need for further research to take a position supporting or opposing these devices [18].

Therefore, this study aimed to evaluate, in a simulated child choking scenario, the ability of parents and teachers (people with a high likelihood of involvement in an FBAO event) to perform the recommended actions for the management of FBAO and to compare it with the use of these two anti-chocking suction devices quickly and correctly.

\section{Methods}

Participants 
Forty-two parents (84.3\%) and eight kindergarten teachers (15.7\%), ( $n=51 ; 54.9 \%$ female) without prior knowledge about suction devices took part voluntarily in this study. Written informed consent on the understanding that the data obtained would be anonymous and used only for research purposes was obtained from all participants. The study was conducted following the 2013 amended Declaration of Helsinki; the protocol was waived by the local Research Ethics Committee because it did not involve the use of participant's health data, the collection of biological samples, or intervention on participants.

\section{Procedure}

We conducted a randomized crossover trial in an in-situ (daycare center) simulated FBAO scenario. Participants $(n=51)$ were asked to act in a simulated choking situation in three different scenarios: 1$)$ performing the recommended protocol [Recommended protocol test]; 2) using LifeVac ${ }^{\circledR}$ device [LifeVac test]; and 3) using DeCHOKER ${ }^{\circledR}$ device [Dechoker test]. This resulted in 153 FBAO events (Figure 1). The tests' performance order was randomised.

In the "Recommended protocol" test participants were provided with instructions of the protocol for airway obstruction according to the international guidelines [4,7] displayed in a wall poster. Following these instructions, they were to respond initially on a simulated victim (a 21-year-old woman, heigh 1.53 $\mathrm{m}$, weight $46.5 \mathrm{~kg}$, member of the research team) who played a mild airway obstruction, which subsequently became severe, and finally, the victim simulated unresponsiveness, so that participants had to perform all the steps of the mentioned protocol.

Regarding LifeVac test and Dechoker test, the solving of the FBAO simulation was carried out with a junior manikin (Resusci Junior QCPR ${ }^{\mathrm{TM}}$; Laerdal) (Figure 1). In both tests, participants were given the antichoking suction devices ( $\mathrm{LifeVac}^{\circledR}$ or DeCHOKER ${ }^{\circledR}$ ) with the manufacturer's leaflet instructions. Participants had not been previously trained and did not have the opportunity to handle or test the antichoking suction devices before the tests.

Neither support nor advices were provided to participants during the tests, assuming that they were alone in the incident scenario. The execution of each of the steps (yes/no and correctly/incorrectly performed) according to the corresponding test was assessed by means of a specific checklist by a researcher. Another team member recorded the time taken to carry out the steps and the overall test time.

\section{Instruments}

Two anti-choking suction devices were used in the present study: $\mathrm{LifeVac}^{\circledR}$ and DeCHOKER ${ }^{\circledR}$. LifeVac ${ }^{\circledR}$ LifeVac (Nesconset, New York, USA) consists of a one-way valve and a plunger attached to a standard face mask (with three different sizes depending on the anthropometric profile of the victim: pediatric, child, and adult mask). To remove the foreign body from the airway, the mask is held over the choking victim's nose and mouth, and then, two repeated movements are required: push and pull handle. $\mathrm{LifeVac}^{\circledR}$ is not recommended for choking victims under $10 \mathrm{~kg}$ bodyweight. 
DeCHOKER ${ }^{\circledR}$ (Concord, North Carolina, USA) is a single device composed of a mask attached to an oropharyngeal tube that needs to be positioned above the tongue, joined to a large cylinder with a plunger. To generate negative pressure, it is necessary to pull the plunger out with force. DeCHOKER ${ }^{\circledR}$ is also available in three different sizes (toddlers, children, and adults) according to the age of the victim, and it is recommended from one year onwards.

This study used for LifeVac test and Dechoker test the manikin Resusci Junior QCPR ${ }^{\mathrm{TM}}$ (Laerdal, Medical AS, Stavanger, Norway) which simulates a 6 year old child. For the LifeVac test the child size mask was used and for the Dechoker test the children device was used (participants did not have to select it, we gave them the right size).

\section{Variables}

Age, gender, weight and height of each participant were registered. In addition, they were asked about whether they had received previous training on choking (if yes, when it had happened); about whether they had witnessed a real FBAO situation (and when it had happened) and, whether they had acted or not. Moreover, they were also asked about their subjective perception of whether they feel they would be able to solve a FBAO situation (yes/no).

In all three tests, the performance of each step (yes/no) and, if done, the correct execution (yes/no) were recorded (Figure 1). To compare quantitatively the three tests, the variable estimated success rate was calculated taking into account whether or not the recommended steps were taken and whether or not they were performed correctly.

The estimated success rate for the "Recommended protocol" test comprised the following dichotomic items: 1) encouraging to cough; 2) giving back blows; 3 ) giving back blows correctly; 4) giving abdominal thrust; 5) giving abdominal thrust correctly; 6 ) continue to 5 back blows and 5 abdominal thrusts; 7 ) continue to 5 back blows and 5 abdominal thrusts correctly; and 8) Starting CPR for victim's unresponsiveness. The estimated success rate for the LifeVac test: 1) inserting the mask into the device, 2) place the mask covering nose and mouth of the victim correctly, 3) fixing the mask to the victim's airway, 4) push in handle, 5) pull handle, and 6) keeping the mask fixed to the victim's airway throughout the procedure. Lastly, the estimated success rate for Dechoker test: 1) place the mask covering nose and mouth of the victim correctly, 2) fixing the mask to the victim's airway, 3) pull the plunger out with force, and 4) keeping the mask fixed to the victim's airway throughout the procedure. Finally, the overall time of the tests and the partial times of each of the phases were recorded (Figure 1).

\section{Statistical Analysis}

Data were analysed with SPSS statistical software (IBM corp., v. 25.0 for Mac). Results are expressed as median (interquartile range) and absolute frequencies (relative frequencies) as appropriate. Nonparametric tests were used after checking the normality of variables using the Kolmogorov-Smirnov test. The non-parametric Friedman test for related samples was used for the comparison of the overall time 
and estimated success rate between the 3 tests (Recommended protocol test, LifeVac test and Dechoker test) and the Wilcoxon signed-rank test for assessed paired differences. McNemar's test was used to compare categorical variables between LifeVac and Dechoker test. A significance level of $p<0.02(0.05 / 3)$ for the paired comparison analyses was considered and a significance level of $p<0.05$ for the rest.

\section{Results}

Anthropometric data and main characteristics of the 51 participants ( $54.9 \%$ female) are shown in Table 1. Nineteen (37.3\%) (the eight kindergarten teachers and eleven parents) had received some prior training on how to handle a FBAO event according to recommended protocol. Of all participants, $11(21.6 \%)$ referred to have witnessed a FBAO incident in the past but only 6 had intervened. Before the tests, participants were asked about their self-confidence for solving a FBAO scenario correctly. Twenty-eight (54.9\%) answered that they would be able to intervene satisfactorily.

Table 2 shows data related to "Recommended protocol" test (overall sample and disaggregated by previous FBAO-training). Less than a half of the participants (45.1\%) encouraged the victim to cough. This percentage was even lower in the case of untrained (31.3\%) compared to trained participants $(68.4 \%$, $p=0.010$ ). Giving back blows was performed by $76.5 \%$ of participants, with significant differences between those trained $(100 \%)$ vs untrained $(73.9 \%)(p=0.026)$. The same was observed for abdominal thrusts, with a $94.1 \%$ of participants performing this step, and significant higher proportion of trained participants (52.6\% trained vs $13.8 \%$ untrained) who have correctly performed it $(p=0.004)$. Thirty participants (58.8\%) stated that they would start CPR when in the last part of the test the victim became unresponsive. Regarding the estimated success rate for the "Recommended protocol" test, overall participants obtained a median score of 50 ( $75 \%$ for those with previous training vs $38 \%$ for those without training, $p=0.003$ ).

The analysis of each step of the FBAO sequence treatment using $\mathrm{LifeVac}^{\circledR}$ and DeCHOKER ${ }^{\circledR}$ anti-choking suction devices is presented in Table 3. Most of the steps were performed correctly by the majority of participants without significant differences between both devices. The poorest performing step was keeping the mask fixed to the victim's airway throughout the procedure, with $43.1 \%$ failing to do so with the LifeVac device and 33.3\% failing to do so with the DeChoker device.

The only variable with significant differences between LifeVac and Dechoker was the time spent performing the test where participants spent a median of $9 \mathrm{sec}$ less to place the LifeVac $^{\circledR}(p<0.001)$ (Table 4). The estimated success rate was similar with both devices.

In terms of estimated success rate (Figure 2), a significantly higher rate was obtained with the two devices compared to the recommended protocol $(p<0.001)$. No significant differences were found between LifeVac ${ }^{\circledR}$ and DeCHOKER ${ }^{\circledR}$.

Finally, significant differences were found when comparing the overall procedure time spent on each of the tests $(p<0.001)(T a b l e 4)$. Participants spent significantly more time with the recommended protocol 
and the DeCHOKER ${ }^{\circledR}$ device than with the LifeVac ${ }^{\circledR}$ device $(p<0.001)$. However, no differences in time were found between the DeCHOKER ${ }^{\circledR}$ and the recommended protocol.

\section{Discussion}

Our study is the first that aimed to assess, in a simulated scenario, the handling of new anti-choking devices ( $\mathrm{LifeVac}{ }^{\circledR}$ and $\mathrm{DeCHOKER} \circledast$ ) and to compare them with the recommended choking protocol by laypeople at risk of witnessing an FBAO: parents and kindergarten teachers. We observed that most participants achieved a higher success rate in managing FBAO using both anti-choking devices than with the currently recommended protocol. However, they often failed fitting and keeping the mask to the victim's airway. When devices were compared with each other, participants needed less time when using the LifeVac ${ }^{\circledR}$, although in both cases, the mean total time was slightly shorter than one minute.

The main goal of the FBAO treatment is the removal of the obstruction as early as possible without injury to the victim, which means that bystanders are the target population to solve it $[19,20]$. Controversy about FBAO management is rooted on the limited evidence supporting these interventions, which are mainly based on case series and experts' opinion, and on the potential harms associated with these techniques [13]. This leads to a continuous search for a safe and effective alternative.

Previously published information and evidence on the new anti-choking devices are extremely limited and unconclusive. The recent systematic review by Dunne et al. [17] includes only five studies about the LifeVac ${ }^{\circledR}$ device, two of them on manikins [21,22], one on a cadaver [23] and the others were case series $[24,25]$ which report a high success rate for FBAO removal, in most cases in the first few attempts. However, these references are seriously biased (industrial involvement, measurement of outcomes, selection, and information bias, with hardly any information on the methodology used, imprecise results...) [17].

Up to now, only two new articles have been published since the above-mentioned review. In one study, the DeCHOKER ${ }^{\circledR}$ device was evaluated in 27 real choking victims, 26 of whom were successfully removed the obstruction with the device [26]. The other study, a manikin randomized crossover trial conducted with medical students, compared abdominal thrust, LifeVac ${ }^{\circledR}$, and DeCHOKER ${ }^{\circledR}$ device and found a higher estimated success rate for FBAO removal with the LifeVac $®$ device [19]. For these reasons, the need for further studies on this issue has been suggested $[16,17]$.

The estimated success rate, calculated by taking into account the correct performance of all steps in each sequence, showed significantly better results for the anti-choking devices (without significant differences between them). In other words, participants found it easier to use the brand-new LifeVac $\circledast$ and DeCHOKER $\circledast$ devices as they did so with fewer errors than following the recommended protocol.

However, it has to be noted that, although instructions were provided for all three situations, we observed that participants followed the instructions more carefully in the case of the anti-choking devices perhaps because they were completely new tools to them. On the other hand, in the case of the recommended 
standard protocol, they often acted instinctively or according to their prior knowledge without strictly paying attention and following the displayed instructions. This may explain why there were more errors while performing the recommended protocol sequence. In fact, only $5.9 \%$ of the participants performed all steps correctly compared to $51 \%$ with LifeVac ${ }^{\circledR}$ and $56.9 \%$ with DeCHOKER ${ }^{\circledR}$ devices.

One of the main problems blamed on these devices is that they can distract rescuers and cause a delay in the recommended techniques (such as back blows and abdominal thrust) $[8,16,17,19]$. However, in our study, participants spent less than one minute to apply the LifeVac ${ }^{\circledR}$ and DeCHOKER ${ }^{\circledR}$ devices to solve the FBAO simulation. Although our study did not assess the effective FBAO successful removal, the results agree with those of the study by Patterson et al. [19] who showed a higher number of successful FBAO removal in a shorter time with the LifeVac ${ }^{\circledR}$ device ( $82 \%$ in the first minute compared to $44 \%$ cases using DeCHOKER® and $67 \%$ using abdominal thrusts). Nevertheless, the three situations are not entirely comparable as the devices are theoretically recommended when the choking protocol fails $[14,15]$.

When devices were compared with each other, both had similar success rates. Of the entire procedure, the most difficult step for the participants was the one related to fitting and keeping the mask to the victim's airway. This is a remarkable fact because although participants spent less time in the process with the LifeVac $\circledast$ device, they had more difficulties with the mask seal. In this line, the successful removal of a FBAO using devices depends on the generation of a strong negative pressure associated with an effective mask seal [19]. Previous studies using facemask also reported difficulty of use, especially for novices and above all with one-hand technique $[27,28]$. In this sense, further studies are needed to corroborate our preliminary results.

Regarding the management of a FBAO simulation acting according to recommended protocol, we have found that most participants (94.1\%) gave abdominal thrusts and many also gave the back blows (76.5\%). However, when it came to performing these steps correctly, we found that more participants who had received prior training did significantly better. As mentioned, the estimated success rate of executing the steps was lower than with the anti-choking devices. And, in turn, participants with prior training achieved a significantly higher rate. Although no previous studies on evaluating the effect of training on the choking recommended protocol have been found, our results might be related to other studies where different methods of training in BLS content, such as AED [29], and adult [30,31] and pediatric [32] CPR, improved performance outcomes.

Based on our results, we consider that the anti-choking devices are easy to use but a short training would be needed to reduce errors and take advantage of the devices' function. Further evidence on the efficacy of these devices is needed in order to be able to recommend their use as previously reported $[17,18]$. In agreement, the 2021 European Resuscitation Council Guidelines of Basic Life Support [33] maintain the prior recommendations for the management of a FBAO and insist that alternative techniques lack sufficient evidence for their introduction into the guidelines at this moment.

\section{Limitations}


Our study is not free of limitations. First, we conducted a simulation manikin study that involves two weaknesses: the manikin doesn't exactly reflect the characteristics of a real victim and participants might have different attitudes compared to a real FBAO scenario. Moreover, the manikin was a standard CPR model, not a specific one for FBAO. Although there are manikins for FBAO situations, they were not created for the evaluation of anti-choking devices effectiveness. Thus, no manikins exist that would allow reliable evaluation of the effectiveness of these devices. On the other hand, for the recommended protocol test we used a real person to simulate the FBAO instead of a manikin due to the particular characteristics of the manikin did not allow the technique to be executed correctly. Our sample was small and specific: parents and teachers in a kindergarten, which makes it necessary to interpret the results with caution and not to extrapolate them to the general population.

In addition, the success rate variable, calculated to compare quantitatively the three situations, has the limitation that in each test was calculated based on a different number of items (recommended protocol 8 items, LifeVac® 6 items, and DeCHOKER® 4 items).

\section{Conclusions}

Untrained laypeople, under simulated conditions and according to the manufacturer's instructions, are able to handle LifeVac ${ }^{\circledR}$ and DeCHOKER ${ }^{\circledR}$ anti-choking devices in less than one minute. However, they have difficulties in applying the current recommended choking protocol. Further studies are needed to confirm whether the new devices could have a role in the FBAO management.

\section{Abbreviations}

FBAO: Foreign body airway obstruction

FDA: Food and Drug Administration

\section{Declarations}

\section{Compliance with Ethical Standards}

Acknowledgments: We would like to thank the participants who made this study possible.

Funding: AC-F (FPU19/02017) is recipient of a pre-doctoral fellowship by the Spanish Ministry of Science, Innovation and University.

Conflicts of interest/Competing interests: The authors declare that they have no conflict of interest.

Availability of data and material: The authors confirm that the main data supporting the findings of this study are available within the article. Additional data of this study are available from the corresponding author (CA-G) on request. 
Code availability: N/A

Authors' contributions: AR-N conceived the idea. All authors designed the methodology. RB-F contacted with the kindergarten. AC-F, CA-G \& ER-R collected the data. AC-F \& CA-G performed the statistical analysis. AC-F wrote the first draft. CA-G carried out the first revision of the manuscript. All the authors reviewed the following versions of the manuscript and approved the final article.

Ethics approval: the protocol was waived by the local Research Ethics Committee because it did not involve the use of participant's health data, the collection of biological samples, or intervention on participants.

Consent to participate: Written informed consent to participate was obtained from all participants.

Consent for publication: Written informed consent to publish the data was obtained from all participants.

\section{References}

1. Committee on Injury, Violence, and Poison Prevention. Prevention of choking among children. Pediatrics 2010;125:601-7. https://doi.org/10.1542/peds.2009-2862

2. Denny SA, Hodges NL, Smith GA. Choking in the Pediatric Population. Am J Lifestyle Med 2014;9:438-441. https://doi.org/10.1177/1559827614554901

3. Eskander A, de Almeida JR, Irish JC. Acute Upper Airway Obstruction. N Engl J Med 2019;381:1940-9. https://doi.org/ 10.1056/NEJMra1811697

4. Perkins GD, Handley AJ, Koster RW, Castrén M, Smyth MA, Olasveengen T, et al. Adult basic life support and automated external defibrillation section Collaborators. European Resuscitation Council Guidelines for Resuscitation 2015: Section 2. Adult basic life support and automated external defibrillation. Resuscitation. 2015;95:81-99. https://doi.org/10.1016/j.resuscitation.2015.07.015

5. American Academy of Pediatrics: Guidelines for emergency medical care in school. Pediatrics 2001;107:435-6. https://doi.org/10.1542/peds.107.2.435

6. Heimlich HJ. A life-saving maneuver to prevent food choking. JAMA 1975;234:398-401.

7. Berg RA, Hemphill R, Abella BS, Aufderheide TP, Cave DM, Hazinski MF, et al. Part 5: adult basic life support: 2010 American Heart Association Guidelines for Cardiopulmonary Resuscitation and Emergency Cardiovascular Care. Circulation 2010;122:S685-705.

8. Van de Voorde P, de Lucas N. A 'foreign body' in the 'foreign body airway obstruction' algorithm. Resuscitation 2020;153:258-9. https://doi.org/10.1016/j.resuscitation.2020.05.030.

9. Guidelines 2000 for Cardiopulmonary Resuscitation and Emergency Cardiovascular Care. Part 3. Adult Basic Life Support. The American Heart Association in collaboration with the International Liaison Committee on Resuscitation. Circulation 2000;102:I22-59. https://doi.org/10.1161/circ.102.suppl_1.I-22 
10. Redding JS. The choking controversy: critique of evidence on the Heimlich maneuver. Crit Care Med 1979;7:475-9.

11. Langhelle A, Sunde K, Wik L, Steen PA. Airway pressure with chest compressions versus Heimlich manoeuvre in recently dead adults with complete airway obstruction. Resuscitation 2000;44:105-8. https://doi.org/10.1016/s0300-9572(00)00161-1.

12. Chillag S, Krieg J, Bhargava R. The Heimlich maneuver: breaking down the complications. South Med J 2010;103:147-50. https://doi.org/ 10.1097/SMJ.0b013e3181c99140.

13. Couper K, Abu Hassan A, Ohri V, Patterson E, Tang HT, Bingham R, et al. Removal of foreign body airway obstruction: A systematic review of interventions. Resuscitation 2020;156:174-81. https://doi.org/10.1016/j.resuscitation.2020.09.007

14. Lifevac [Internet]. [Cited 2020 Mar 12]; Available from: https://lifevac.life.

15. Dechoker [Internet]. [Cited 2020 Mar 12]; Available from: https://www.dechoker.com.

16. Rodríguez-Ruiz E, Abelairas-Gómez C, Barcala-Furelos R, Rodríguez-Núñez A. Foreign body airway obstruction and anti-choking suction devices. Time to step forward. Resuscitation 2020;157:133-4. https://doi.org/10.1016/j.resuscitation.2020.09.038

17. Dunne CL, Peden AE, Queiroga AC, Gómez-González C, Valesco B, Szpilman D. A systematic review on the effectiveness of anti-choking suction devices and identification of research gaps. Resuscitation 2020;153:219-26. https://doi.org/10.1016/j.resuscitation.2020.02.021.

18. Olasveengen TM, Mancini ME, Perkins GD, Avis S, Brooks S, Castrén M, et al. Adult basic life support: international consensus on cardiopulmonary resuscitation and emergency cardiovascular care science with treatment recommendations. Resuscitation 2020;156:A35-79. https://doi.org/10.1016/j.resuscitation.2020.09.010.

19. Patterson E, Tang HT, Ji C, Perkins GD, Couper K. The efficacy and usability of suction-based airway obstruction: a manikin randomised crossover trial. Resuscitation Plus 2021;5:1000067. https://doi.org/10.1016/j.resplu.2020.100067.

20. Kinoshita K, Azuhata T, Kawano D, Kawahara Y. Relationships between pre-hospital characteristics and outcome in victims of foreign body airway obstruction during meals. Resuscitation 2015;88:637. https://doi.org/10.1016/j.resuscitation.2014.12.018.

21. Lih-Brody L, Singer M, Brody E. Lifevac: a novel apparatus for the resuscitation of the adolescent choking victim. Ann Emerg Med 2017;70:S149-50.

22. Lih-Brody L, Lih A, Brody E, Singer M. LifeVac: a novel apparatus to resuscitate a choking victim. Am J Gastroenterol 2015;110:S695.

23. Juliano M, Domingo R, Mooney M, Trupiano A. Assessment of the LifeVac, an anti-choking device, on a human cadaver with complete airway obstruction. Am J Emerg Med 2016;34:1673-4. https://doi.org/10.1016/j.ajem.2016.03.047.

24. Saperstein DM, Pugliesi PR, Ulteig C, Schreiber N. Successful use of a novel device called the LifeVac to resuscitate choking victims - worldwide results. Int J Clin Ski 2018;12:216-9. 
25. Lih-Brody L, Benenson A, Chin R. Successful resuscitation of choking victims using a Lifevac, a nonpowered portable suction device: real world experience: 2017 President Poster Award: 1762. Am J Gastroenterol 2017;112.

26. Bhanderi BG, Hil SP. Evaluation of Dechoker, an airway clearance device (ACD) used in adult choking emergencies within the adult care home sector: a mixed methods case study. Front Public Health 8:541885. https://doi.org/10.3389/fpubh.2020.541885.

27. Joffe AM, Hetzel S, Liew EC. A two-handed jaw-thrust technique is superior to the one-handed "ECclamp" technique for mask ventilation in the apneic unconscious person. Anesthesiology 2010;113:873-9.

28. Gerstein NS, Carey MC, Braude DA, Tawil I, Petersen TR, Derily L, et al. Efficacy of facemask ventilation techniques in novice providers. J Clin Anesthesia 2013;25:193-7. https://doi.org/10.1016/j.jclinane.2012.10.009.

29. Yeung J, Okamoto D, Soar J, Perkins GD. AED training and its impact on skill acquisition, retention and performance-a systematic review of alternative training methods. Resuscitation 2011;82:657-64. https://doi.org/10.1016/j.resuscitation.2011.02.035

30. Anderson R, Sebaldt A, Lin Y, Cheng A. Optimal training frequency for acquisition and retention of high-quality CPR skills: A randomized trial. Resuscitation 2019;135:153-161. https://doi.org/10.1016/j.resuscitation.2018.10.033.

31. González-Salvado C, Rodríguez-Ruiz E, Abelairas-Gómez C, Ruano-Raviña A, Peña-Gil C, GonzálezJuanatey JR, Rodríguez-Núñez A. Training adult laypeople in basic life support. A systematic review. Rev Esp Cardiol 2020;73:53-68. https://doi.org/10.1016/j.rec.2018.11.013.

32. Donoghue A, Heard D, Griffin R, Abbadessa ML, Gaines S, Je S, et al. Longitudinal effect of high frequency training on CPR performance during simulated and actual pediatric cardiac arrest. Resuscitation Plus 6:100117. https://doi.org/10.1016/j.resplu.2021.100117.

33. Olasveengen TM, Semeraro F, Ristagno F, Castren M, Handley A, Kuzovlev A, et al. European Resuscitation Council Guidelinez 2021: Basic Life Support. Resuscitation 2021;161:98-114. https://doi.org/10.1016/j.resuscitation.2021.02.009

\section{Tables}

Table 1. Characteristics of the participants. 


\begin{tabular}{|lll|}
\hline Age in years $_{\text {Weight }}$ in kg & $40.0(36.0-43.0)$ \\
\hline Height in $\mathrm{m}$ & & $70.0(58.0-80.0)$ \\
\hline Gender & Male & $23(45.7)$ \\
\hline Training FBAO & Female & $28(54.9)$ \\
\hline Years since training & Yes & $19(37.3)$ \\
\hline Witnessed FBAO & No & $32(62.7)$ \\
\hline Years since witnessed FBAO & & $5.0(2.0-8.0)$ \\
\hline Intervened FBAO & Yes & $11(21.6)$ \\
\cline { 2 - 3 } & No & $40(78.4)$ \\
\hline Feel to be able to solve the FBAO & Yes & $28(54.9)$ \\
\cline { 2 - 3 } & Yes & $6(54.5)$ \\
\cline { 2 - 3 } & No & $23(45.1)$ \\
\hline
\end{tabular}

FBAO: Foreign Body Airway Obstruction

Continuous variables [median (interquartile range)]

Categorical variables [absolute frequency (relative frequency)]

Table 2. Descriptive analysis of the performance of the steps recommended for the treatment of the adult victim with FBAO. 


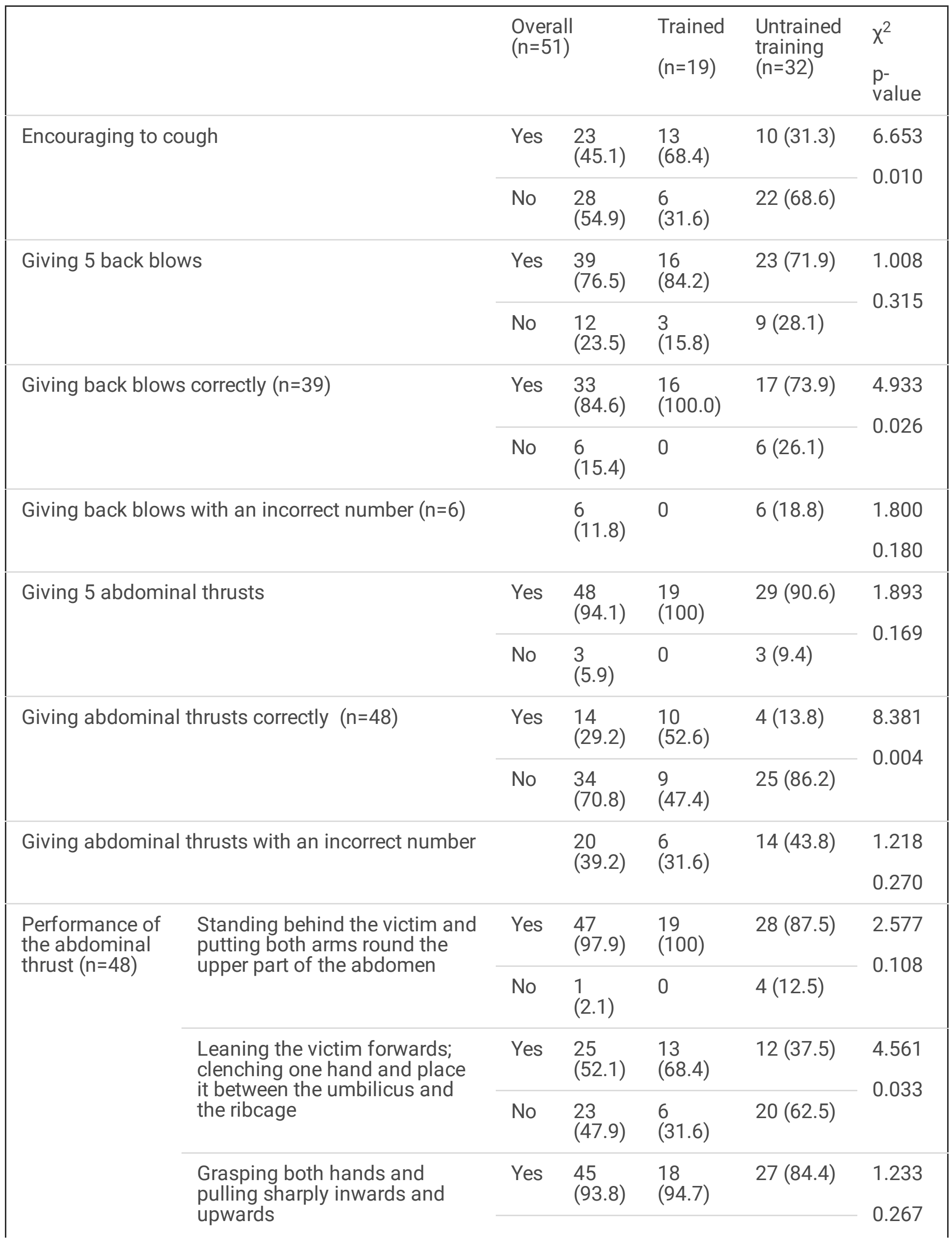




\begin{tabular}{|c|c|c|c|c|c|}
\hline & No & $\begin{array}{l}3 \\
(6.3)\end{array}$ & $1(5.3)$ & $5(15.6)$ & \\
\hline \multirow[t]{2}{*}{ Continue to 5 back blows and 5 abdominal thrusts } & Yes & $\begin{array}{l}18 \\
(35.3)\end{array}$ & $\begin{array}{l}9 \\
(47.4)\end{array}$ & $9(28.1)$ & \multirow{2}{*}{0.164} \\
\hline & No & $\begin{array}{l}33 \\
(64.7)\end{array}$ & $\begin{array}{l}10 \\
(52.6)\end{array}$ & $23(71.9)$ & \\
\hline \multirow[t]{2}{*}{$\begin{array}{l}\text { Continue to } 5 \text { back blows and } 5 \text { abdominal thrusts } \\
\text { correctly }(n=18)\end{array}$} & Yes & $\begin{array}{l}12 \\
(66.7)\end{array}$ & $\begin{array}{l}7 \\
(77.8)\end{array}$ & $5(55.6)$ & \multirow{2}{*}{$\begin{array}{l}1.000 \\
0.317\end{array}$} \\
\hline & No & $\begin{array}{l}6 \\
(33.3)\end{array}$ & $\begin{array}{l}2 \\
(22.2)\end{array}$ & $4(44.4)$ & \\
\hline \multirow[t]{2}{*}{ Continue to abdominal thrust only } & & \multirow{2}{*}{$\begin{array}{l}6 \\
(11.8)\end{array}$} & \multirow{2}{*}{$\begin{array}{l}2 \\
(10.5)\end{array}$} & \multirow[t]{2}{*}{$4(12.5)$} & 0.010 \\
\hline & & & & & 0.920 \\
\hline \multirow[t]{2}{*}{ Starting CPR for victim's unresponsiveness } & Yes & $\begin{array}{l}30 \\
(58.8)\end{array}$ & $\begin{array}{l}12 \\
(63.2)\end{array}$ & $18(56.3)$ & \multirow{2}{*}{$\begin{array}{l}0.235 \\
0.628\end{array}$} \\
\hline & No & $\begin{array}{l}21 \\
(41.2)\end{array}$ & $\begin{array}{l}7 \\
(36.8)\end{array}$ & $14(43.8)$ & \\
\hline \multirow[t]{2}{*}{ Performed all steps } & Yes & $\begin{array}{l}8 \\
(15.7)\end{array}$ & $\begin{array}{l}5 \\
(26.3)\end{array}$ & $3(9.4)$ & \multirow[t]{2}{*}{$\begin{array}{c}2.687 \\
0.108\end{array}$} \\
\hline & No & $\begin{array}{l}43 \\
(84.3)\end{array}$ & $\begin{array}{l}14 \\
(73.7)\end{array}$ & $29(90.6)$ & \\
\hline \multirow[t]{2}{*}{ Performed all steps correctly } & Yes & $\begin{array}{l}3 \\
(5.9)\end{array}$ & $\begin{array}{l}2 \\
(10.5)\end{array}$ & $1(3.1)$ & 1.180 \\
\hline & No & $\begin{array}{l}48 \\
(94.1)\end{array}$ & $\begin{array}{l}17 \\
(89.5)\end{array}$ & $31(96.9)$ & 0.277 \\
\hline Estimated success rate (in \%) & \multicolumn{2}{|c|}{$\begin{array}{l}50.0(38.0- \\
75.0)\end{array}$} & $\begin{array}{l}75.0 \\
(50.0- \\
88.0)\end{array}$ & $\begin{array}{l}38.0 \\
(25.0- \\
63.0)\end{array}$ & $0.003^{\dagger}$ \\
\hline Time until back blows (in seconds) & \multicolumn{2}{|c|}{$\begin{array}{l}13.1(10.7- \\
15.3)\end{array}$} & $\begin{array}{l}12.4 \\
(10.7- \\
14.2)\end{array}$ & $\begin{array}{l}14.1 \\
(10.2- \\
15.8)\end{array}$ & $0.271^{\dagger}$ \\
\hline Time until abdominal thrust (in seconds) & \multicolumn{2}{|c|}{$\begin{array}{l}25.2(19.1- \\
32.9)\end{array}$} & $\begin{array}{l}23.5 \\
(16.2- \\
26.4)\end{array}$ & $\begin{array}{l}27.0 \\
(20.8- \\
34.2)\end{array}$ & $0.137^{\dagger}$ \\
\hline Overall procedure time (in seconds) & \multicolumn{2}{|c|}{$\begin{array}{l}48.3(42.1- \\
60.7)^{-1}\end{array}$} & $\begin{array}{l}48.6 \\
(43.0- \\
59.6)\end{array}$ & $\begin{array}{l}47.4 \\
(41.7- \\
62.1)\end{array}$ & $0.778^{\dagger}$ \\
\hline $\begin{array}{l}\text { Overall time of participants who completed all } \\
\text { steps }(n=8) \text { (in seconds) }\end{array}$ & \multicolumn{2}{|c|}{$\begin{array}{l}55.1(46.9- \\
68.7)\end{array}$} & $\begin{array}{l}60.7 \\
(48.7- \\
73.4)\end{array}$ & $46.8^{*}$ & $0.143^{\dagger}$ \\
\hline
\end{tabular}

FBAO: Foreign Body Airway Obstruction; CPR: cardiopulmonary resuscitation 
* $\mathrm{n}=3$ Unable to calculate interquartile range

Continuous variables [median (interquartile range)]

Categorical variables [absolute frequency (relative frequency)]

${ }^{\dagger}$ Mann-Whitney U test

Table 3. Descriptive analysis of the performance of the treatment of the adult victim with FBAO with LifeVac ${ }^{\circledR}$ and DeCHOKER ${ }^{\circledR}$ device.

\begin{tabular}{|c|c|c|c|c|c|}
\hline & \multicolumn{2}{|c|}{ LifeVac $^{\circledR}$} & \multicolumn{2}{|c|}{ DeCHOKER $^{\circledR}$} & $\begin{array}{l}\mathrm{p}- \\
\text { valor }\end{array}$ \\
\hline \multirow[t]{2}{*}{ Inserting the mask into the device } & Yes & $\begin{array}{l}46 \\
(90.2)\end{array}$ & \multirow[t]{2}{*}{-} & & \multirow[t]{2}{*}{--} \\
\hline & No & $5(9.8)$ & & & \\
\hline \multirow[t]{2}{*}{$\begin{array}{l}\text { Place the mask covering nose and mouth of the victim } \\
\text { correctly }\end{array}$} & Yes & $\begin{array}{l}40 \\
(78.4)\end{array}$ & Yes & $\begin{array}{l}46 \\
(90.2)\end{array}$ & \multirow[t]{2}{*}{$0.109^{\dagger}$} \\
\hline & No & $\begin{array}{l}11 \\
(21.6)\end{array}$ & No & $5(9.8)$ & \\
\hline \multirow[t]{2}{*}{ Fixing the mask to the victim's airway } & Yes & $\begin{array}{l}42 \\
(82.4)\end{array}$ & Yes & $\begin{array}{l}45 \\
(88.2)\end{array}$ & \multirow[t]{2}{*}{$0.453^{\dagger}$} \\
\hline & No & $9(17.6)$ & No & $6(11.8)$ & \\
\hline \multirow[t]{2}{*}{ Push in handle } & Yes & $\begin{array}{l}50 \\
(98.0)\end{array}$ & \multirow{2}{*}{\multicolumn{2}{|c|}{-}} & \multirow[t]{2}{*}{-} \\
\hline & No & $1(2.0)$ & & & \\
\hline \multirow[t]{2}{*}{$\begin{array}{l}\text { Pull handle }\left(\text { LifeVac }^{\circledR}\right) / / \text { Pull the plunger out with } \\
\text { force }\left(\text { DeCHOKER }{ }^{\circledR}\right)\end{array}$} & Yes & $\begin{array}{l}50 \\
(98.0)\end{array}$ & Yes & $\begin{array}{l}50 \\
(98.0)\end{array}$ & \multirow[t]{2}{*}{$1.000^{\dagger}$} \\
\hline & No & $1(2.0)$ & No & $1(2.0)$ & \\
\hline \multirow[t]{2}{*}{$\begin{array}{l}\text { Keeping the mask fixed to the victim's airway } \\
\text { throughout the procedure }\end{array}$} & Yes & $\begin{array}{l}29 \\
(56.9)\end{array}$ & Yes & $\begin{array}{l}34 \\
(66.7)\end{array}$ & \multirow[t]{2}{*}{$0.405^{\dagger}$} \\
\hline & No & $\begin{array}{l}22 \\
(43.1)\end{array}$ & No & $\begin{array}{l}17 \\
(33.3)\end{array}$ & \\
\hline \multirow[t]{2}{*}{ Performed all steps correctly } & Yes & $\begin{array}{l}26 \\
(51.0)\end{array}$ & Yes & $\begin{array}{l}29 \\
(56.9)\end{array}$ & \multirow[t]{2}{*}{$0.678^{\dagger}$} \\
\hline & No & $\begin{array}{l}25 \\
(49.0)\end{array}$ & No & $\begin{array}{l}22 \\
(43.1)\end{array}$ & \\
\hline Estimated Success rate & \multicolumn{2}{|c|}{$\begin{array}{l}100(83.0- \\
100.0)\end{array}$} & \multicolumn{2}{|c|}{$\begin{array}{l}100(75.0- \\
100.0)\end{array}$} & $0.796 *$ \\
\hline
\end{tabular}


FBAO: Foreign Body Airway Obstruction

Continuous variables [median (interquartile range)]

Categorical variables [absolute frequency (relative frequency)]

* Wilcoxon test

${ }^{+}$McNemar test

Table 4. Comparison of procedure time between recommended protocol, LifeVac $^{\circledR}$ and DeCHOKER ${ }^{\circledR}$.

\begin{tabular}{|c|c|c|c|c|c|c|c|}
\hline & $\begin{array}{l}\text { Recommended } \\
\text { protocol }\end{array}$ & LifeVac $^{\circledR}$ & DeCHOKER ${ }^{\circledR}$ & $\begin{array}{l}\mathrm{p}- \\
\text { value }\end{array}$ & $\begin{array}{l}\mathrm{RP} v s \\
\mathrm{~L}\end{array}$ & $\begin{array}{l}\mathrm{RP} v s \\
\mathrm{D}\end{array}$ & $\mathrm{L} v s \mathrm{D}$ \\
\hline \multirow{2}{*}{$\begin{array}{l}\text { Time until } \\
\text { device fitting } \\
\text { on the victim }\end{array}$} & & 31.9 & 39.6 & \multirow{2}{*}{$\begin{array}{l}< \\
0.001 *\end{array}$} & & & \\
\hline & & $\begin{array}{l}(24.8- \\
38.2)\end{array}$ & $\begin{array}{l}(29.8- \\
57.2)\end{array}$ & & & & \\
\hline \multirow[t]{2}{*}{ Overall time } & 48.3 & 39.3 & 55.6 & \multirow{2}{*}{$\begin{array}{l}< \\
0.001^{\dagger}\end{array}$} & \multirow{2}{*}{$<.001 *$} & \multirow[t]{2}{*}{$0.115^{\star}$} & \multirow{2}{*}{$<.001 *$} \\
\hline & $(42.1-60.7)$ & $\begin{array}{l}(31.4- \\
44.4)\end{array}$ & $\begin{array}{l}(38.9-71 . \\
0)\end{array}$ & & & & \\
\hline
\end{tabular}

L: LifeVac ${ }^{\circledR} ; \mathrm{D}:$ DeCHOKER ${ }^{\circledR} ;$ RP: Recommended protocol

* Wilcoxon test

${ }^{\dagger}$ Friedman test

\section{Figures}




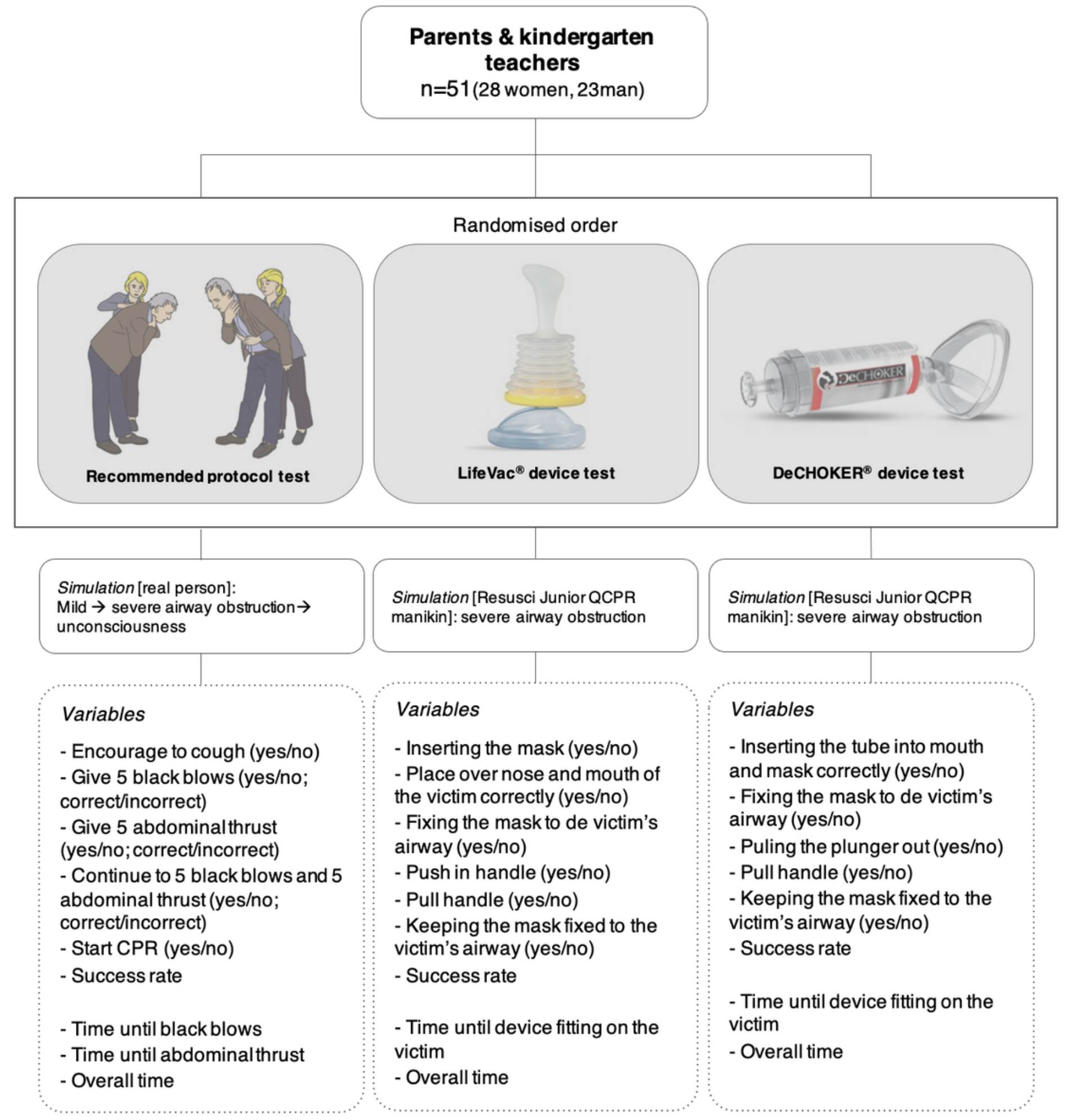

\section{Figure 1}

Flow chart of the design of the study. 


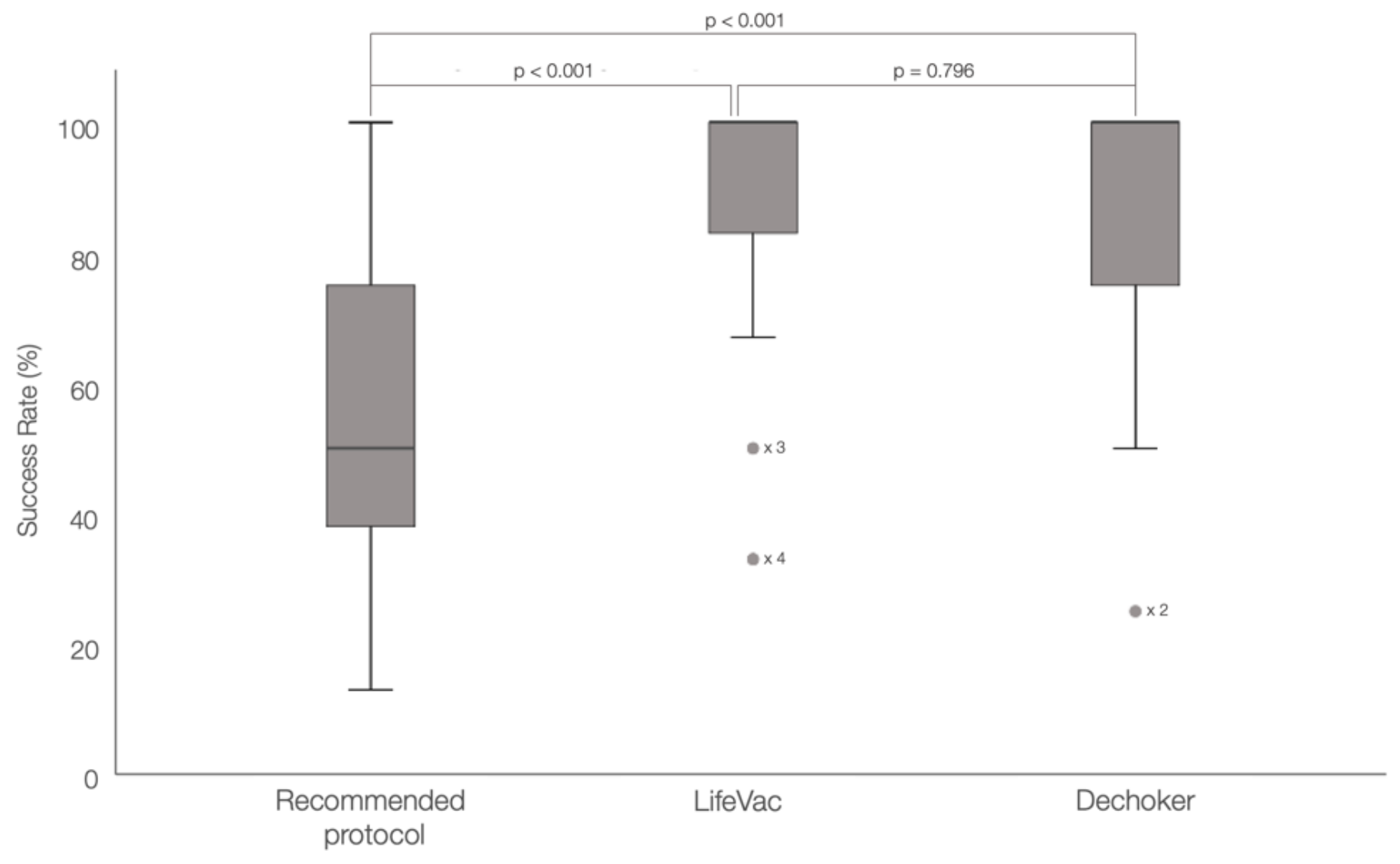

Figure 2

Comparison of estimated success rate between three tests. Grey dots symbolize outliers. 